\title{
O TURISMO NO RIO GRANDE DO NORTE
}

José Alexandre Berto de Almada ${ }^{1}$

\section{Resumo}

O presente artigo aborda o espaço geográfico do turismo no Rio Grande do Norte. A primeira parte discute a produção do espaço geográfico pelo turismo a partir das políticas públicas relacionadas a essa atividade no estado, entre 1980 e 2017, principalmente o PRODETUR/NE. A segunda apresenta, com base nos dados estatísticos da SETUR, do MTUR e decretos oficiais, a espacialização e especialização produtiva do turismo no Rio Grande do Norte, objetivando entender o papel do turismo para o desenvolvimento econômico do estado. O turismo não é uma atividade que consegue promover um desenvolvimento econômico para todo o estado, uma vez que está polarizada em Natal e quando se interioriza não consegue obter bons indicadores turísticos e econômicos para além do Polo Costa das Dunas.

Palavras-chave: Turismo; Rio Grande do Norte; Políticas públicas; Geografia do Turismo.

\section{THE GEOGRAPHIC SPACE OF TOURISM IN RIO GRANDE DO NORTE}

\begin{abstract}
This article addresses the geographic space of tourism in Rio Grande do Norte. The first part discusses the production of geographic space by tourism based on public policies related to this activity in the state, between 1980 and 2017, mainly PRODETUR/NE. The second presents, based on statistics from SETUR, MTUR and official decrees, the spatialization and specialization productive of tourism in Rio Grande do Norte, aiming to understand the role of tourism for the economic development of the state. Tourism is not an activity that can promote economic development for the entire state, as it is polarized in Natal and when it is internalized it cannot obtain good tourist and economic indicators beyond the Costa das Dunas Polo.
\end{abstract}

Keywords: Tourism; Rio Grande do Norte; Public Policies; Tourism Geography.

\section{L'ESPACE GEOGRAPHIQUE DU TOURISME AU RIO GRANDE DO NORTE}

\section{Résumé}

Cet article traite de l'espace géographique du tourisme au Rio Grande do Norte. La première partie traite de la production d'espace géographique par le tourisme sur la base des politiques publiques liées à cette activité dans l'état, entre 1980 et 2017,

\footnotetext{
${ }^{1}$ Doutorando do Programa de Pós-Graduação em Geografia da UFPE. Professor do Departamento de Geografia da Universidade do Estado do Rio Grande do Norte (Campus central).Email: josealmada@ uern.br. 
principalement PRODETUR / NE. La seconde présente, sur la base des statistiques de SETUR, MTUR et des décrets officiels, la spatialisation et la spécialisation productive du tourisme au Rio Grande do Norte, dans le but de comprendre le rôle du tourisme dans le développement économique de l'état. Le tourisme n'est pas une activité susceptible de promouvoir le développement économique pour l'ensemble de l'État, car il est polarisé au Natal et, lorsqu'il est internalisé, il ne peut pas obtenir de bons indicateurs touristiques et économiques au-delà de la Costa das Dunas Polo.

Mots-clés: Tourisme; Rio Grande do Norte; politiques publiques; Géographie du Tourisme

\section{INTRODUÇÃO}

O turismo no Rio Grande do Norte ganha destaque na pauta econômica entre as décadas de 1980 e 1990, tendo como referência o modelo de sol e praia, que valoriza como atrativo turístico as características naturais do lugar como o clima tropical, as praias e as dunas.

Porém, essa não foi a primeira experiência em turismo do estado potiguar, nas primeiras décadas do século XX começam a aparecer no estado os primeiros hotéis para suprir as necessidades de acomodação daqueles que visitavam o estado em função do trabalho, com destaque para o Grande Hotel Natal, no bairro da Ribeira, o mais importante da cidade naquele momento por concentrar empresas e prédios públicos, inaugurado no ano de 1939 para atender a demanda da aviação internacional das empresas Compagnie Génerale Aéropostale, francesa, Sidicato Condor, alemã, Panair do Brasil, representante da Pan-american dos EUA, e a Ala Littoria, italiana, ambas também situadas no bairro da Ribeira (COSTA, 2011).

Embora o Grande Hotel funcionou por um curto momento, entre final da década de 1930 e início da década de 1950, a sua inauguração marcou o início do turismo no Rio Grande do Norte, no qual a partir da base teórica da geografia de Milton Santos Costa (2011) utiliza esteve evento para iniciar a periodização do turismo no estado, levando em consideração as variáveis-chave técnica, política e materialidade divididas nas escalas mundo, Brasil e Rio Grande Norte, no qual a autora denomina esse primeiro período de “Os primeiros passos para a implantação do turismo no RN (1939-1970)", onde ações voltadas para o turismo foram apenas iniciativas pontuais, visando a possibilidade de implantá-lo (COSTA, 2011). 
O segundo período do turismo potiguar destacado por Costa (2011), "Caminhando para efetiva implantação do turismo no RN", ocorre entra as décadas de 1970 e 1980 e teve com principal característica a participação do estado na promoção do turismo por meio da criação em 1971 da Empresa de Promoções e Desenvolvimento do Turismo no Rio Grande do Norte - EMPROTURN, pela Lei 4025/71, "que constituía uma empresa de economia mista com autonomia administrativa e financeira, cuja competência era de coordenar e dirigir as ações governamentais no âmbito do turismo" (GONÇALVES; SERAFIM, 2006, p.7), extinta em 1995 no governo de Garibaldi Alves (1995-2002), no momento em que foi criada a Secretaria de Turismo, Industria e Comércio (STINC), no ano seguinte, a pasta de turismo é separada da indústria e comércio e assumindo uma secretaria exclusiva para a formulação de políticas de turismo para o Rio Grande do Norte, criando assim a Secretária de Turismo (SETUR) pela Lei Complementar 144/96.

Atualmente o estado do RN conta com uma Empresa Potiguar de Promoção Turística - EMPROTUR - criada em 2007 pela Lei Complementar 339/07, tem objetivos semelhantes a sua antecessora EMPROTURN, porém, voltada exclusivamente para a promoção turística, de acordo com Art. 2 a EMPROTUR “[...] terá como finalidade promover o Estado do Rio Grande do Norte como Destino turístico em âmbito nacional e internacional". (RIO GRANDE DO NORTE, p.1 2007).

O final deste período as bases do turismo no Rio Grande do Norte, pautado no atual modelo de Sol e Praia que se concentra em Natal, é pensando por meio do projeto Parque das Dunas/Via Costeira, onde atualmente está localizada a região concentrada do turismo potiguar, que começa a ser planejado a partir do Decreto 82.669 no ano de 1978, que cede por aforamento terrenos da União para a construção desse projeto, sendo inaugurada quase cinco anos depois em 15 de março de 1983 (COSTA, 2011).

O terceiro período destacado por Costa (2011), o turismo depois da Via Costeira, entre as décadas de 1980 e 1990 é o momento em que a atividade turística passa a ser encarada como uma atividade importante para a economia do Rio Grande do Norte, com destaque para a implementação de dez hotéis de grande porte na Via Costeira entre 1984 e 1997, essa base possibilitou para a década seguinte que em 2006 o estado alcançasse uma receita turística na cifra de $\mathrm{R} \$ 1.340,5$ milhão nesse ano, sendo que $76 \%^{2}$ dessa receita corresponde somente a cidade de Natal, e uma renda gerada de $\mathrm{R} \$ 2.345,9$ milhões, com um impacto sobre o Produto Interno Bruto (PIB) do estado de 11,4\% (SETUR, 2013).

\footnotetext{
${ }^{2}$ Natal em 2006 teve uma receita turística de $\mathrm{R} \$ 1.023,3$ milhão (SETUR, 2013). 
Além da construção da Via Costeira a política pública do Programa de Desenvolvimento do Turismo no Nordeste (PRODETUR/NE), com a primeira fase iniciada em 1991, teve um impacto direto para o turismo, enquanto atividade econômica, pudesse contribuir na década seguinte com pouco mais de $11 \%$ do PIB do estado, dando início ao quarto período do turismo no Rio Grande do Norte, segundo Costa (2011), justamente “o turismo no RN depois do PRODETUR”, entre os anos de 1991 e 2011, finalizando nesse ano pois é o ano da publicação da dissertação de mestrado da autora.

Tendo como recorte temporal o quarto período do turismo destacado por Costa (2011), o presente artigo, dividido em duas partes, aborda o espaço geográfico do turismo no Rio Grande do Norte. A primeira discute a produção do espaço geográfico pelo turismo a partir das políticas públicas relacionadas a essa atividade, no período de 1980 até 2017 , sobretudo as ações do PRODETUR/NE, que incidem sobre o estado potiguar. A segunda apresenta, com base nos dados estatísticos da SETUR, do MTUR e dos decretos de criação dos polos turísticos do estado, a espacialização e especialização produtiva do turismo no Rio Grande do Norte, tendo como objetivo central entender o papel do turismo para o desenvolvimento econômico do estado.

\section{A PRODUÇÃo do ESPAÇO GEOGRÁfiCO PELO TURISMO NO RIO GRANDE DO NORTE A PARTIR DAS POLÍTICAS PÚBLICAS}

O Rio Grande do Norte experimentou o fenômeno do turismo entre o final da década de 1930 e início da 1980, porém esse não conseguiu destacar-se enquanto atividade econômica que produz ou modifica o espaço geográfico em função de sua existência, pois, “[...] as cidades litorâneas do Nordeste não se enquadram, até a primeira metade dos anos 1980, no fenômeno de valorização turística intenso e em escala internacional" (DANTAS; ALVES, 2017, p.13), tendo a ainda embrionária atividade turística destinada a atender a demanda de políticos e empresários que visitavam o estado, uma vez que as que políticas destinadas a essa atividade eram pontuais e desarticulada (ibidem), onde um [...] reduzido número de empresários da terra, de pequeno e médio porte, confiou no futuro da nova 'indústria'. Investiu no turismo, com muita dedicação e esforço, aplicando o pouco mais ou nada que dispunham de suas economias" (Cardoso,1997, p.38), nesse período gestacional do turismo potiguar. 
A partir dos anos 1980 o turismo deixa de ser um sonho ou uma aventura empresarial e começa a se destacar no cenário econômico potiguar, principalmente a partir da inserção de Natal no roteiro do turismo no Nordeste, a quem atribui esse fato, “[...] sobretudo, graças a fatores naturais como sua localização geográfica, o sol tropical, clima agradável durante praticamente todo o ano, e seu litoral de belas praias banhadas pelo Atlântico Sul" (LIMA, 2003, p. 36), porém, os elementos naturais que compõem a paisagem do litoral potiguar figuram no plano de marketing para atrair visitantes em busca de sol e praia, esses por si só não são responsáveis pelo crescimento da atividade turística no estado, pois sempre estiveram presentes na configuração territorial do litoral do estado, ou seja, o turismo não é um dado natural, mas uma construção sócio-espacial no qual participam ativamente o Estado, o Mercado e o Turista, que tem a sua emergência no território a partir de um evento, no Rio Grande do Norte, o Estado teve um papel ativo na constituição do evento que possibilitou o turismo de transcender de uma atividade relegada a poucos visitantes para um crescente turismo de massa nas décadas seguintes, despertando o desejo de uma classe média e alta do sudeste do país por um Nordeste diferente daquele pintado por Graciliano Ramos em Vidas Secas.

Mais do que uma vocação natural para o turismo em função do sol e da praia, é a participação institucional do Rio Grande do Norte que estrutura a atividade turística na capital ao apostar no turismo como alternativa para crise econômica das atividades tradicionais de base rural das décadas de 1970 e 1980 (AZEVEDO, 2013).

A crise econômica no Rio Grande do Norte, durante o período citado, é agravada pelo contexto nacional que vinha de uma crise iniciada nos anos 1970, "[...] sobretudo devido aos efeitos dos choques do petróleo, em 1973 e 1979" (VARGAS; FELIPE, 2015, p. 131), levando o presidente Enersto Geisel (1974-1979) elaborar o II Plano Nacional de Desenvolvimento (PND), que

frente ao estrangulamento externo ocasionado pela alta extraordinária dos preços internacionais do petróleo, o governo Geisel desencadeou um ambicioso programa de substituição de importações sob a égide do Estado, mas com maciça utilização de empréstimos externos. (SALLUM JR; KUGELMAS, 1991, p.149).

O II PND apontava o turismo como atividade econômica para o desenvolvimento do país e, especificamente, para o Nordeste brasileiro, cuja atividade fazia parte da estratégia urbana com o objetivo de realizar "a ordenação da ocupação da orla marítima, 
preservando-se o patrimônio histórico e valorizando-se a beleza paisagística, com vistas ao desenvolvimento do turismo interno e internacional" (BRASIL, 1974, p.89), valorizando o modelo de turismo de massa pautado no binômio sol e praia como atrativo turístico.

Conforme comentam Dantas e Alves (2017) o II PDN foi um marco para o turismo no Nordeste, pois, influenciou diretamente ação dos estados na elaboração de políticas públicas voltadas para promover o turismo enquanto atividade para o desenvolvimento econômico do estado, e para o Rio Grande do Norte, o plano foi responsável por influenciar a concepção da política do Megaprojeto Parque das Dunas.

Segundo Harvey (2005, p.85) "o Estado, inevitavelmente, envolve-se na administração de crises e age contra a tendência de queda da margem de lucro." No contexto do Brasil o II PND é um exemplo empírico desse papel do Estado, principalmente ao investir em infraestrutura para sustentar novas atividades econômicas, pois, as crises periódicas do capitalismo possuem "o efeito de expandir a capacidade produtiva e de renovar as condições de acumulação adicional" (HARVEY, 2005, p.47).

É nesse momento de tensão dialética da crise capitalista, entre a saturação e a renovação ou criação de uma atividade econômica, que Harvey destaca a necessidade de se realizar um ajuste espacial, isto é, “[...] o impulso insaciável do capitalismo para resolver sua tendência para crises internas pela expansão geográfica e reestruturação geográfica" (HARVEY, 2001, p.24), no cenário do Rio Grande do Norte o turismo surge como um ajuste espacial, que por meio da ação do estado é construído a Via Costeira, espaço que recebeu os primeiros grandes hotéis voltados para esse novo período do turismo potiguar.

Em continuidade ao ajuste espacial pelo turismo o PRODETUR/NE advém no começo da década de 1990 com o objetivo de promover a infraestrutura necessária para consolidar a emergência turismo no território litorâneo nordestino por meio de financiamento público-privado entre os estados abrangidos por essa política e o Banco Intramericano de Desenvolvimento (BID), com sede Washington, EUA.

O PRODETUR atuou no Nordeste Brasileiro a partir da ideia de que a pobreza dessa região está associada ao fato de que o "[...]o Nordeste perdeu sua posição de centro de crescimento após a industrialização do Brasil, ocorrida no início do século XX" 
(BANCO DO NORDESTE DO BRASIL S.A., 2005, p.4), argumento esse rebatido por

Andrade (1993, p.13-14), ao destacar que

\begin{abstract}
é falsa a ideia generalizada, nas regiões mais ricas do país, de que o Nordeste é uma região pobre por ter uma pequena e antiquada produção agrícola e industrial. A pobreza do Nordeste deriva sobretudo da má distribuição da renda - há um forte contraste entre o nível de vida das classes dominantes e o do povo -, da grande concentração da propriedade fundiária, do sistema econômico nacional que transformou a região em fornecedora de matérias primas e mão de obra pouco qualificada para as regiões economicamente mais dinâmicas, e da apropriação das riquezas regionais por grupos econômicos internacionais e de outras áreas do país.
\end{abstract}

Sem se aprofundar no debate sobre a origem da pobreza do Nordeste, o PRODETUR, em sua primeira fase, é muito mais um ajuste espacial resultante da pareceria do estado com o grande capital internacional para dar continuidade a expansão geográfica para conter a crise interna do capitalismo no Nordeste do que um programa para combater a pobreza estigmatizada da região, à vista disso,

[...] Nasceu o Programa de Desenvolvimento do Turismo no Nordeste do Brasil - PRODETUR/NE, concebido como um Programa Global de Investimentos Múltiplos, com recursos repassados para os Estado participantes via contratos de sub-empréstimo. O objetivo básico do PRODETUR/NE I foi contribuir para o desenvolvimento socioeconômico do Nordeste do Brasil por meio do desenvolvimento da atividade turística. Especificamente, o Programa contemplou iniciativas do setor público em infraestrutura básica e desenvolvimento institucional voltadas tanto para a melhoria das condições de vida das populações beneficiadas, quanto para a atração de investimentos do setor privado ligados ao turismo. (BANCO DO NORDESTE DO BRASIL S.A., 2005 p.5. Grifo do autor).

Para o Rio Grande do Norte, um dos estados contemplados pelo PRODETUR, a reestruturação produtiva não mudou o quadro de contraste entre a classe dominante e o restante do povo, uma vez que "as práticas autoritárias provenientes do discurso tradicionalista agrário-política se fixaram na capital e fizeram do turismo no Rio Grande do Norte um mecanismo para sua reprodução do poder" (DANTAS; ALVES, 2017, p. 26), resultando em cenário de práticas econômicas modernas conivente com a estrutura tradicional que mantem o poder político-econômico concentrado nas mãos de poucas famílias.

Ao final do programa em 2005, US\$ 38,24 milhões foram distribuídos de forma desigual entre os poucos municípios beneficiados pelo PRODETUR-NE, com $82 \%$ dos recursos distribuídos entre Natal, com 24\%, e Parnamirim com 58\% desses recursos. 
Os recursos destinados ao ente estadual não foram utilizados em obras de melhoraria de infraestrutura, mas sim para o desenvolvimento institucional e para a elaboração de estudos e projetos relacionados ao turismo, recebendo US\$1.086.961,06 e US\$ 776.790,23 respectivamente para esse fim.

O município de Parnamirim recebeu a maioria dos recursos do PRODETUR/NE para a ampliação do aeroporto internacional Augusto Severo situado nesse município, com 53\% do total de recursos do programa para esse fim, aplicando US\$ 20,18 milhões. Além do aeroporto outros componentes também foram beneficiados, como os investimentos de $15 \%$, quase US\$ 6 milhões, em rodovias, utilizados, principalmente, no prolongamento da BR-101 que conecta Natal ao aeroporto Augusto Severo, desativado desde 2014 em função da construção do aeroporto Aluísio Alves em São Gonçalo do Amarante, ao litoral norte, finalizando no município de Touros onde localiza-se o marco zero desta rodovia.

A partir do financiamento conjunto entre o estado e o BID por meio do PRODETUR/NE, o turismo no Rio Grande do Norte deixou de ser uma possibilidade para tornar-se uma atividade que contribuiu no processo de reestruturação do produtiva do território potiguar, aumentando a receita turística no estado de US\$ 40,8 milhões em 1986 para US\$ 562,4 milhões no ano de 2005 (EMPROTURN, 1991; SETUR, 2008) quando finalizou a primeira fase do PRODETUR/NE.

Em continuidade aos avanços aos investimentos públicos é realizada a segunda fase do PRODETUR/NE, que inicia em 2002, com a primeira fase ainda em andamento, a partir do contrato assinado entre Banco do Nordeste e o BID, “[...] com as autorizações do Senado Federal para a contratação da garantia da União ao Empréstimo e a concessão do aval da União aos submutuários para superar o problema existente de limite de financiamento estatal por parte do BNB" (EQUIPE PCR, 2012, p. 2), previsto para terminar em 2007, porém, esse prazo foi prorrogado duas vezes finalizando em 27 de março de 2012, data em que foi desembolsado o último empréstimo. (ibidem).

O ponto inovador desta fase é a aplicação do conceito de polo turístico como ferramenta para regionalizar a atividade turística em cada estado, entendendo polo enquanto "[...] grupos de municípios contíguos com atrativos turísticos similares ou complementares, que têm a determinação comum de desenvolver a capacidade local necessária para uma gestão turística sustentável” (EQUIPE PCR, 2012, p. 3). No 
total dez polos, distribuídos na região Nordeste e no Norte de Minas Gerais ${ }^{3}$, foram beneficiados pelo financiamento do PRODETUR/NE II. No Rio Grande do Norte foi criado o Polo Costa das Dunas, que se estende ao longo do litoral oriental do estado e tem Natal como a cidade central, geograficamente e economicamente.

Ao final do PRODETUR/NE II, em 2012, foram aplicados US\$410,9 milhões na Bahia, Ceará, Minas Gerais, Pernambuco, Piauí e no Rio Grande do Norte, que recebeu US\$ 37,5 milhões, quase um milhão a menos em relação a fase anterior, aplicados em Tibau do Sul, Nísia Floresta, Extremoz, Ceará-Mirim, Maxaranguape, Touros, Arês, Goianinha, Nísia Floresta, São José de Mipibu, Senador Georgino Avelino, Extremoz, Natal, São Gonçalo do Amarante e Parnamirim.

O relatório de término de projeto, ao contrário do relatório referente a primeira fase do PRODETUR, não especificou o montante gasto em cada ação, apenas listando e espacializando-as. O mapa 1 destaca os municípios que foram beneficiados pelas ações pela primeira fase do programa com o preenchimento de hachuras verticais e os beneficiados pela segunda fase com hachuras horizontais, havendo sobreposição nos municípios que foram beneficiados pelas as duas fases. No mapa 1 considera o Polo Costa das Dunas (PCD) considerando os municípios presentes na configuração de 2005, pelo decreto N. 18.186/2005, e pela de 2017, pelo decreto N.26.661/17.

\footnotetext{
${ }^{3}$ São os polos: do Descobrimento, que engloba a Costa do Descobrimento e a Costa das Baleias, Polo Litoral Sul, Polo Salvador e Entorno e o Polo da Chapada Diamantina, no estado da Bahia; do Vale do Jequitinhonha, em Minas Gerais; Polo Costa das Dunas, no Rio Grande do Norte; Polo Costa dos Arrecifes, em Pernambuco; Polo Costa do Sol, no Ceará; e Polo Costa do Delta, no Piauí.
} 


\section{MAPA 1: ESPACIALIZAÇÃO DAS AÇÕES DO PRODETUR/NE FASES I E II}

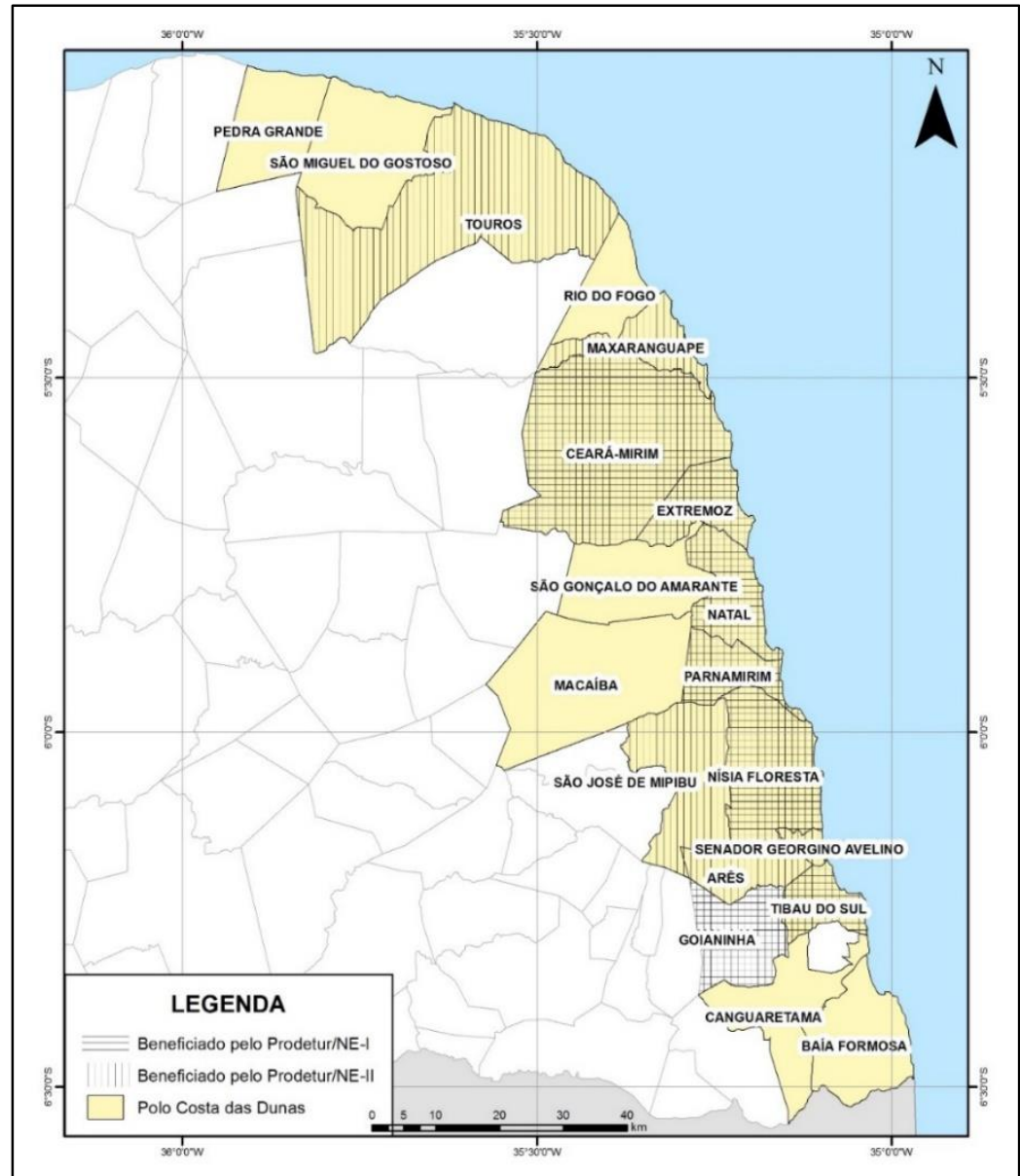

Fonte: Elaborado pelo autor, com base em BANCO DO NORDESTE DO BRASIL S.A (2005); EQUIPE PCR (2012).

Entre os anos de 1994 e 2012 o PRODETUR/NE aplicou no estado US\$ 75,7 milhões, contribuindo diretamente para estruturar material e imaterialmente a atividade turística no Rio Grande do Norte, com base no modelo de turismo de massa de sol e praia centralizado na capital Natal.

As obras de infraestrutura, no sentindo material, principalmente as que valorizam as vias de acesso aérea, com a ampliação do aeroporto Augusto Severo, e terrestre na ampliação e restauração das rodovias que conectam o litoral oriental a Natal, com destaque para a rodovia estadual RN-063, popularmente conhecida como Rota do Sol, que liga a praia de Ponta Negra, na capital, a praia de Pipa, em Tibau do Sul, e a rodovia federal BR-101 sentido norte interligando a capital ao litoral norte do Polo Costa das Dunas. 
As ações de sentindo imaterial, como a criação da Secretária de Turismo do Estado do Rio Grande do Norte - SETUR, que passa a elaborar estudos e projetos relacionados a implementação, gestão e diagnóstico da atividade turística, contribuindo para estruturar uma agenda de políticas públicas para o turismo no Rio Grande do Norte. Ao final das ações do PRODETUR/NE em 2012 a atividade turística, estima-se, um impacto de 11,2\% sobre o PIB estadual no ano de 2012 (SETUR, 2013).

Com base nos dados econômicos, a capital do estado concentrou em 2017 16\% do PIB do Rio Grande do Norte ${ }^{4}$ (IBGE, 2019a), porém, no que diz respeito ao turismo, Natal concentrou quase $100 \%$ da receita desta atividade entre os anos de 1996 e 2004, passando a diminuir essa proporção a partir do ano de 2005, conforme demonstra o gráfico 1.

\section{GRÁFICO 1: RENDA DO TURISMO EM NATAL E RIO GRANDE DO NORTE EM DÓLAR (US\$) 1986-2012}

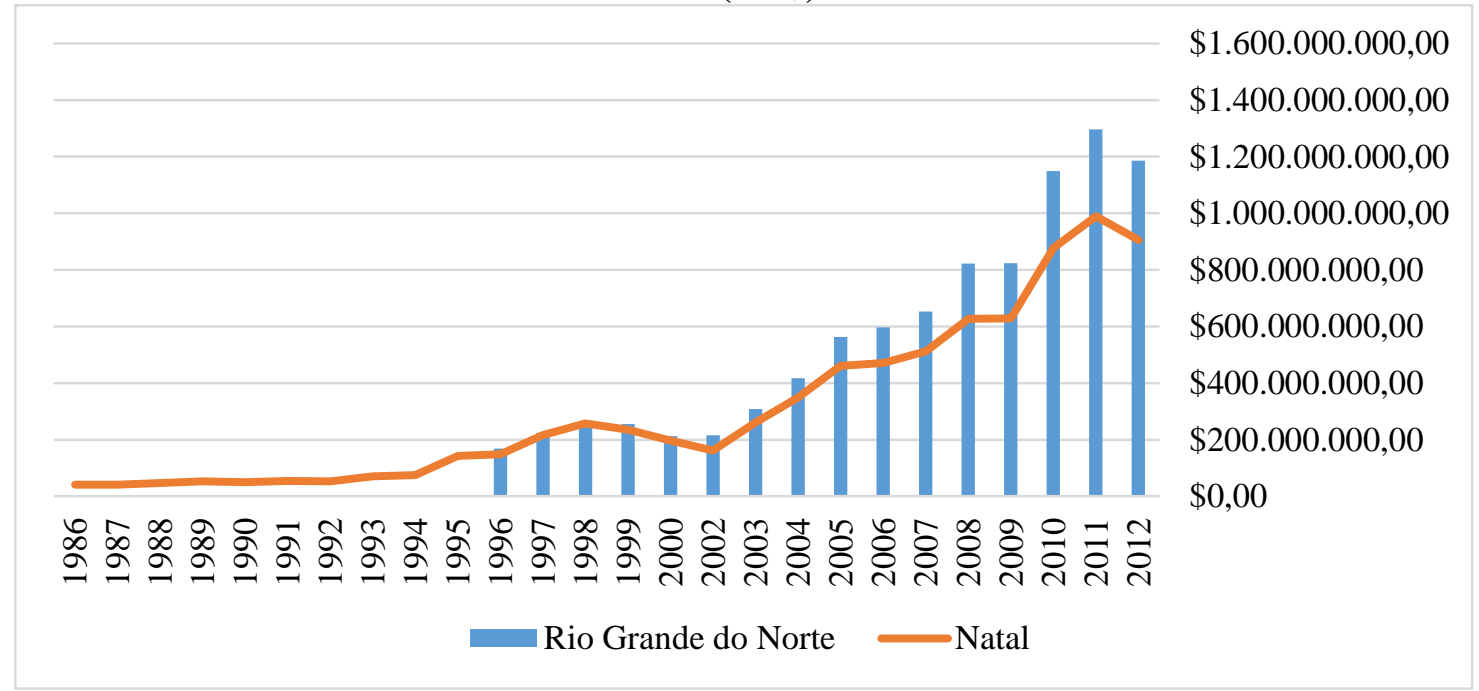

Fonte: EMPROTUR (1991) e SETUR (1997; 1998; 2000; 2008 e 2013).

Apesar do turismo com o PRODETUR/NE II objetivou "[...] aumentar as receitas provenientes da atividade turística e melhorar a capacidade de gestão das mesmas por parte dos Estados e Municípios" (EQUIPE PCR, 2012, p.3), este objetivo não conseguiu se realizar para além da capital do estado, contribuindo para a polarização do turismo no Polo Costa das Dunas, sobretudo em Natal.

\footnotetext{
${ }^{4}$ Em 2017 o Rio Grande do Norte teve o PIB aproximando de R \$ 13,5 bilhões e Natal um PIB aproximando de R \$ 2,2 bilhões (IBGE, 2019).
} 


\title{
ESPACIALIZAÇÃO E ESPECIALIZAÇÃO DOS POLOS TURÍSTICOS NO RIO GRANDE DO NORTE
}

No Rio Grande do Norte, além do Polo Costa das Dunas, região beneficiada pela primeira e segunda fase do PRODETUR/NE, são criados mais três polos turísticos, o Polo Costa Branca pelo decreto n. ${ }^{\circ}$ 18.187/05; o Polo Turístico Seridó pelo decreto $\mathrm{n}^{\circ}$ 18.429/05; o Polo Turístico Serrando pelo decreto $n^{\circ}$ 20.624/08, e o Polo Turístico Agreste/Trairi pelo decreto $\mathrm{n}^{\circ}$ 21.390/09.

Em 2017 é publicado o decreto No 26.661 que dispõe sobre os Polos Turísticos do Estado do Rio Grande do Norte e dá outras providências, que congrega os cinco polos turísticos do estado em um único decreto, “

\begin{abstract}
considerando a necessidade de unificar a legislação que define os Polos de Turismos do Rio Grande do Norte, visando à atualização dos municípios que os compõem, tendo em vista as diretrizes estabelecidas pelas Portarias $\mathrm{n}^{\circ} 205$, de 9 de dezembro de 2015, e $\mathrm{n}^{\circ}$ 172, de 11 de julho de 2016, do Ministério do Turismo (RIO GRANDE DO NORTE, p.1, 2017).
\end{abstract}

Esse decreto revoga os antigos decretos de criação e altera a composição municipal de cada polo, adicionado e removendo municípios, conforme mostra o Mapa 2, no qual, os municípios preenchidos com hachuras diagonais foram os removidos e os preenchidos por pontilhados foram os adicionados pelo Decreto N. 26.661/17.

Além da regionalização dos municípios em polos de acordo “[...] com potencialidades turísticas semelhantes, a fim de promover a estruturação, o planejamento e o desenvolvimento do turismo sustentável, respeitando as tradições e práticas sociais e culturais" (RIO GRANDE DO NORTE, p.1, 2017). Também foi criado para cada polo e para o município de Natal um Plano de Desenvolvimento Integrado do Turismo Sustentável (PDITS), sendo esse um pré-requisito para os municípios acessarem os recursos do PRODETUR Nacional, tendo base a articulação de

conceitos-chaves, fundamentais em sua elaboração e leitura conjunta, isto é, a ideia de Planejamento como procedimento de melhor previsão; a ideia de Desenvolvimento como diretriz que se encaminha ao futuro previsto; e a noção de Sustentabilidade como meio de organizar o desenvolvimento no presente e futuro. (BRASIL, 2011, p.18).

Os PDITS destinado para polos turísticos têm como objetivo "[...] promover a interiorização do turismo, tendo como objetivo central aumentar as fontes de renda e o 
emprego formal no setor para que este não fique apenas concentrado em Natal e arredores" (BRASI, 2016, p.30).

\section{MAPA 2 - POLOS TURÍSTICO DO RIO GRANDE DO NORTE}

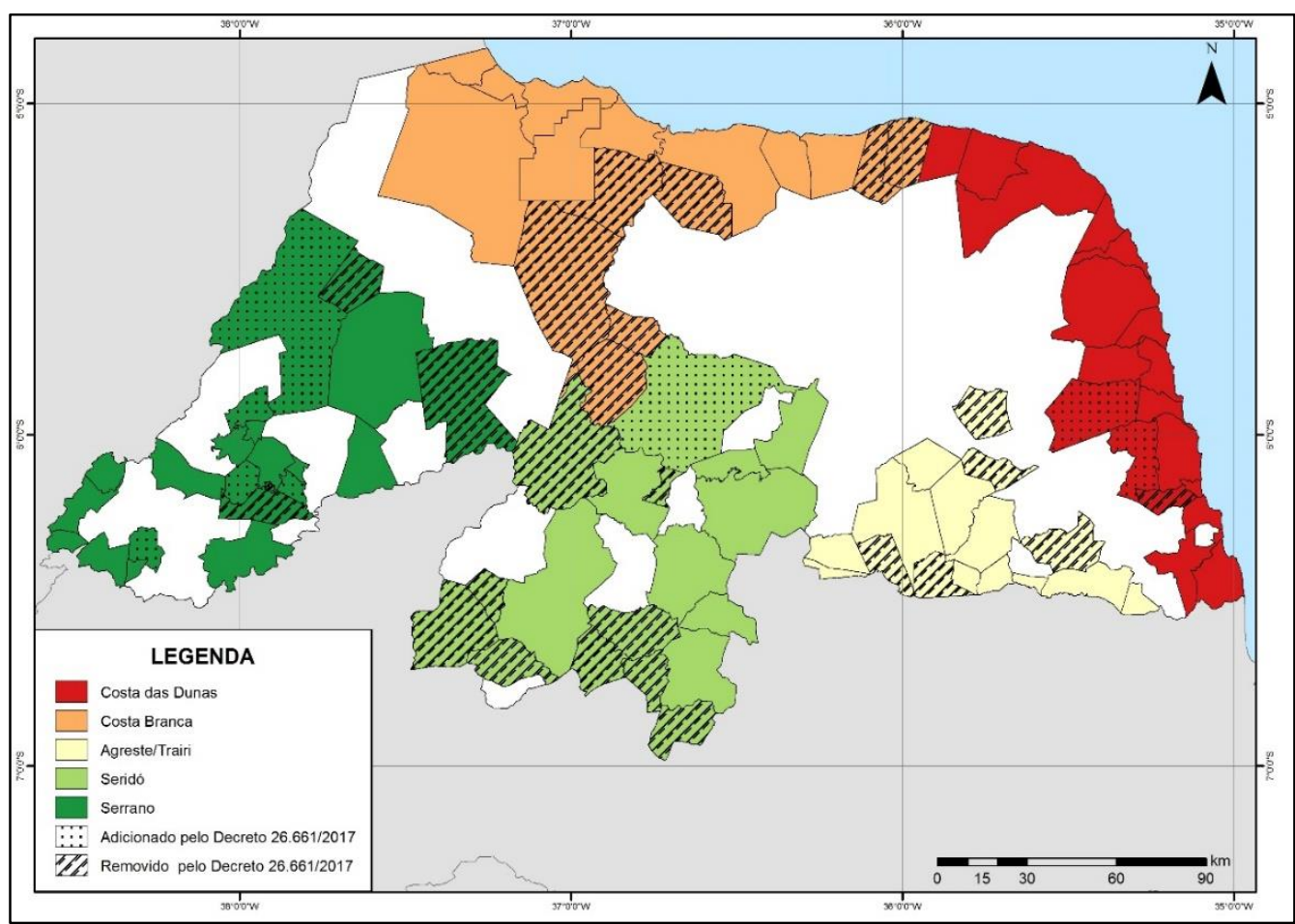

Fonte: Elaborado pelo autor com base RIO GRANDE DO NORTE (2005a; 2005b; 2005c; 2008; 2009 e 2017).

Com a criação dos polos turísticos e de seus respectivos PDTIS houve uma espacialização do turismo pelo interior do estado, porém, quando levado em consideração os indicadores turísticos relacionado ao setor hoteleiro, como os meios de hospedagem, unidades habitacionais e leitos, mostra que a atividade turística no Rio Grande do Norte não conseguiu se dispersar, continuando concentrada no Polo Costa das Dunas, sobretudo no município de Natal.

As tabelas 1 e 2 destacam os dados relacionados ao turismo em cada polo turístico, a primeira contabiliza os meios de hospedagem $(\mathrm{MH})$ e as unidades habitacionais $(\mathrm{UH}) \mathrm{e}$ a segunda o fluxo turístico no estado, tanto os do meio hoteleiro quantos os de outros meios. 
TABELA 1: MEIOS DE HOSPEDAGEM, UNIDADES HABITACIONAIS E LEITOS NORIO GRANDE DO NORTE - SET-2015

\begin{tabular}{|c|c|c|c|c|c|c|}
\hline & MH & $\begin{array}{c}\text { Participação } \\
\text { nos MH no } \\
\text { RN - \% }\end{array}$ & $\begin{array}{c}\text { UH- } \\
\text { SET/2015 }\end{array}$ & $\begin{array}{c}\text { Participação } \\
\text { nas UH no } \\
\text { RN - \% }\end{array}$ & Leitos & $\begin{array}{c}\text { Participação } \\
\text { nos Leitos } \\
\text { no RN - \% }\end{array}$ \\
\hline $\begin{array}{c}\text { Rio Grande } \\
\text { do Norte }\end{array}$ & 625 & 100 & 18.636 & 100 & 52.550 & 100 \\
\hline $\begin{array}{c}\text { P. Costa das } \\
\text { Dunas }\end{array}$ & 473 & 75,7 & 14.846 & 79,7 & 42.892 & 81,6 \\
\hline $\begin{array}{c}\text { P. Costa } \\
\text { Branca }\end{array}$ & 65 & 10,4 & 1.926 & 10,3 & 4.771 & 9,1 \\
\hline P. Seridó & 28 & 4,5 & 683 & 3,7 & 1.730 & 3,3 \\
\hline P. Serrano & 22 & 3,5 & 510 & 2,7 & 1.493 & 2,8 \\
\hline $\begin{array}{c}\text { P. } \\
\text { Agreste/Trairi }\end{array}$ & 24 & 3,8 & 321 & 1,7 & 850 & 1,6 \\
\hline $\begin{array}{c}\text { Outros } \\
\text { Municípios }\end{array}$ & 13 & 2,1 & 350 & 1,9 & 814 & 1,5 \\
\hline
\end{tabular}

Fonte: BRASIL (2016).

\section{TABELA 2: FLUXO TURÍSTICO DO RIO GRANDE DO NORTE - 2015}

\begin{tabular}{|c|c|c|c|c|c|c|}
\hline & \multicolumn{2}{|c|}{ Doméstico } & \multicolumn{2}{c|}{ Internacional } & \multirow{2}{*}{ Total } & $\begin{array}{c}\text { Participação no } \\
\text { total }-\%\end{array}$ \\
\cline { 2 - 5 } & Hoteleiro & Outros & Hoteleiro & Outros & 100 \\
\hline $\begin{array}{c}\text { Rio Grande do } \\
\text { Norte }\end{array}$ & 1.229 .621 & 789.461 & 145.913 & 53.776 & 2.218 .771 & 74,8 \\
\hline $\begin{array}{c}\text { P. Costa das } \\
\text { Dunas }\end{array}$ & 919.861 & 590.584 & 109.155 & 40.229 & 1.659 .828 & 9,7 \\
\hline $\begin{array}{c}\text { P. Costa } \\
\text { Branca }\end{array}$ & 119.335 & 76.618 & 14.161 & 5.219 & 215.333 & 3,4 \\
\hline P. Seridó & 42.319 & 27.170 & 5.022 & 1.851 & 76.361 & 2,6 \\
\hline P. Serrano & 31.600 & 20.288 & 3.750 & 1.382 & 57.020 & 1,6 \\
\hline $\begin{array}{c}\text { P. } \\
\text { Agreste/Trairi }\end{array}$ & 19.889 & 12.770 & 2.360 & 870 & 35.889 & 1,8 \\
\hline $\begin{array}{c}\text { Outros } \\
\text { Municípios }\end{array}$ & 21.686 & 13.923 & 2.573 & 948 & 39.131 & \\
\hline
\end{tabular}

Fonte: BRASIL (2016).

Os cinco polos turísticos do Rio Grande do Norte se espacializam por todo o território potiguar, estando presente em cada região imediata e intermediária do estado ${ }^{5}$, porém, a atividade turística se especializou no litoral do Polo Costa das Dunas, no qual, concentrou $75,7 \%$ dos meios de hospedagem; $79,7 \%$ das unidades habitacionais; $81,6 \%$ dos leitos e 74,8\% do fluxo turístico do Rio Grande do Norte, ano de 2015, ou seja, embora haja a intenção de se interiorizar a atividade turística, os investimentos do

\footnotetext{
${ }^{5}$ A Divisão Regional do Brasil em Regiões Geográficas Imediatas e Regiões Geográficas Intermediárias 2017 apresenta um novo quadro regional vinculado aos processos sociais, políticos e econômicos sucedidos em território nacional desde a última versão da Divisão Regional do Brasil publicada na década de 1990. (IBGE, 2019b)
} 
PRODETUR/NE não conseguiram se espalhar com efetividade econômica para o desenvolvimento local para além da área de influência urbana de Natal, que polariza dentro do PCD e no estado essa atividade.

A tabela 3 mostra o cenário de polarização turística dentro do PCD para o ano de 2009, em Natal concentrou 50,1\% dos meios de hospedagem, 72,7\% das unidades habitacionais e $73 \%$ dos leitos. Além da capital do estado, o município de Tibau do Sul também apresentou números significativos, em relação aos outros municípios que apresentaram taxas abaixo de 5\% nos indicadores selecionados, em função da praia de Pipa, uma estação turística que apresenta uma relativa autonomia na atração de turistas, aparecendo com $21,1 \%$ dos meios de hospedagem, $14,1 \%$ das unidades habitacionais e $14,2 \%$ dos leitos.

\section{TABELA 3: MEIOS DE HOSPEDAGEM, UNIDADES HABITACIONAIS E LEITOS NOS MUNICÍPIOS DO POLO COSTA DAS DUNAS - 2009}

\begin{tabular}{|c|c|c|c|c|c|c|}
\hline Município & $\mathrm{MH}$ & $\begin{array}{c}\text { Participação } \\
\text { dos MH no } \\
\text { PCD -\% }\end{array}$ & UH & $\begin{array}{c}\text { Participação } \\
\text { das UH no } \\
\text { PCD - \% }\end{array}$ & Leitos & $\begin{array}{c}\text { Participação } \\
\text { dos Leitos no } \\
\text { PCD - \% }\end{array}$ \\
\hline PCD & 393 & 100 & 12.414 & 100 & 35.645 & 100 \\
\hline Arez & 01 & 0,2 & 02 & 0 & 04 & 0 \\
\hline Baía Formosa & 14 & 3,7 & 120 & 1 & 345 & 1 \\
\hline Canguaretama & 10 & 2,5 & 122 & 1 & 371 & 1 \\
\hline Ceará-Mirim & 11 & 2,8 & 91 & 0,7 & 240 & 0,7 \\
\hline Extremoz & 06 & 1,5 & 169 & 1,4 & 522 & 1,5 \\
\hline Macaíba & 02 & 0,5 & 29 & 0,2 & 89 & 0,2 \\
\hline Maxaranguape & 11 & 2,8 & 73 & 0,6 & 203 & 0,6 \\
\hline Natal & 197 & 50,1 & 9.021 & 72,7 & 26.106 & 73,3 \\
\hline Nísia Floresta & 09 & 2,3 & 324 & 2,6 & 372 & 1 \\
\hline Parnamirim & 07 & 1,8 & 254 & 2 & 853 & 2,4 \\
\hline Pedra Grande & 02 & 0,5 & 21 & 0,2 & 50 & 0,1 \\
\hline Rio do Fogo & 05 & 1,3 & 53 & 0,4 & 165 & 0,5 \\
\hline $\begin{array}{c}\text { São Gonçalo do } \\
\text { Amarante }\end{array}$ & 0 & 0 & 0 & 0 & 0 & 0 \\
\hline $\begin{array}{c}\text { São José do } \\
\text { Mipibu }\end{array}$ & 05 & 1,3 & 97 & 0,8 & 500 & 1,4 \\
\hline $\begin{array}{c}\text { São Miguel do } \\
\text { Gostoso }\end{array}$ & 19 & 4,8 & 142 & 1,1 & 400 & 1,1 \\
\hline $\begin{array}{l}\text { Sen. Georgino } \\
\text { Avelino }\end{array}$ & 0 & 0 & 0 & 0 & 0 & 0 \\
\hline Tibau do Sul & 83 & 21,1 & 1.751 & 14,1 & 5.082 & 14,2 \\
\hline Touros & 11 & 2,8 & 145 & 1,7 & 343 & 1 \\
\hline
\end{tabular}

FONTE: BRASIL (2011).

Com base nos dados do PCD de 2009, destacado na tabela 3, e os de 2015, da tabela 5 , verifica-se um incremento de $20,3 \%$ no número de meios de hospedagem, indo 
de 393 para 473, de 19,6\% no número de unidades habitacionais, indo de 12.414 para 14.846 e de $20,3 \%$ no número de leitos, passando de 35.645 para 42.892, representando um crescimento médio desses indicadores de $20,1 \%$, com uma taxa de crescimento anual média de $3,3 \%$.

Com base no crescimento médio dos indicadores hoteleiros do PCD, entre os anos de 2009 e 2015, é possível projetar os dados para o Rio Grande do Norte para o ano de 2009, aplicando negativamente a taxa de crescimento aos valores de 2015, para dimensionar a concentração da atividade turística no PCD, sobretudo em Natal para o ano de 2009, conforme segue na tabela 4:

\section{TABELA 4: CONCENTRAÇÃO DOS MEIOS DE HOSPEDAGEM DE NATAL, PCD EM RELAÇÃO AO RIO GRANDE DO NORTE - 2009}

\begin{tabular}{|c|c|c|c|c|c|c|}
\hline & MH & $\begin{array}{c}\text { Participação } \\
\text { dos MH no } \\
\text { RN*_\% }\end{array}$ & UH & $\begin{array}{c}\text { Participação } \\
\text { das UH no } \\
\text { RN*- \% }\end{array}$ & Leitos & $\begin{array}{c}\text { Participação dos } \\
\text { Leitos no RN* - \% }\end{array}$ \\
\hline RN* & $\mathbf{4 9 9}$ & $\mathbf{1 0 0}$ & $\mathbf{1 4 . 8 9 0}$ & $\mathbf{1 0 0}$ & $\mathbf{4 1 . 9 8 7}$ & $\mathbf{1 0 0}$ \\
\hline PCD & 393 & $\mathbf{7 8 , 7}$ & 12.414 & 83,4 & 35.645 & 84,9 \\
\hline Natal & 197 & 39,4 & 9.021 & 60,6 & 26.106 & 62,2 \\
\hline
\end{tabular}

*Projeção para o ano 2009 com base na taxa média de crescimento do PCD entre 2009 e 2015.

Fonte: BRASIL $(2011 ; 2016)$.

Na projeção para o ano de 2009, Natal só não detinha a maioria dos meios de hospedagem, apresentando 39,4\% contra 60,6\% dos outros 166 municípios do Rio Grande do Norte, porém, levando em consideração as unidades habitacionais e os leitos os números revelam a concentração desses indicadores em Natal, agrupando 60,6\% e $62,2 \%$ respectivamente, mesmo que haja uma melhor distribuição dos meios de hospedagem pelo estado é na capital que se encontram as maiores ofertas de unidades habitacionais e de leitos por meio de hospedagem, ou seja, de hotéis e pousadas com maior capacidade de acolhimento dos turistas.

Os dados das tabelas 1 e 4 mostram que o objetivo de interiorizar a atividade turística por meio da criação dos polos turísticos não foi efetiva, pois, a variação da participação dos indicadores hoteleiros do PCD no Rio Grande do Norte em relação aos outros polos reduziram em média 3,3\% entre 2009 e 2015, destacando ainda, uma realidade desigual no cenário turístico potiguar, onde há uma predileção de investimentos no Polo Costa das Dunas. 
Além dos indicadores contidos nos PDTIS dos polos turísticos Agreste/Trairi e Costa das Dunas, também é possível espacializar o atividade turística no Rio Grande do Norte a partir dos dados contidos no Mapa do Turismo, uma política pública para dar suporte ao no art. $5^{\circ}$, inciso VI, da Lei $\mathrm{n}^{\circ} 11.771$, de 17 de setembro de 2008 , que objetiva

promover, descentralizar e regionalizar o turismo, estimulando Estados, Distrito Federal e Municípios a planejar, em seus territórios, as atividades turísticas de forma sustentável e segura, inclusive entre si, com o envolvimento e a efetiva participação das comunidades receptoras nos benefícios advindos da atividade econômica. (BRASIL, 2008, p.2).

Oficializada pela Portaria ${ }^{\circ} 144$, de 27 de agosto de 2015, e utiliza como variável para a regionalização dos municípios os:

I - número de estabelecimentos formais cuja atividade principal é hospedagem (Relação Anual de Informações Sociais - RAIS/ Ministério do Trabalho e Emprego);

II - número de empregos formais no setor de hospedagem (Relação Anual de Informações Sociais - RAIS/Ministério do Trabalho e Emprego);

III - estimativa de turistas a partir do Estudo de Demanda Doméstica (Fundação Instituto de Pesquisas Econômicas - FIPE/Ministério do Turismo); e IV - estimativa de turistas a partir do Estudo de Demanda Internacional. (BRASIL, 2015, p.2).

Conforme o Art. $3^{\circ}$ da portaria 144/15, os municípios são agrupados em cinco categorias, de A à E, conforme resultado obtido em análise de cluster. Atualmente existem duas categorizações, uma de 2016 e outra de 2017. Com base nos dados da categorização de 2017 temos os seguintes resultados para os polos turísticos do Rio Grande do Norte:

TABELA 5: DADOS DO MAPA DO TURISMO DOS POLOS TURÍSTICOS DO RIO GRANDE DO NORTE - 2017

\begin{tabular}{|c|c|c|c|c|c|c|c|c|}
\hline Polo & EMH $^{*}$ & Em \% & $\mathrm{MH}^{* *}$ & $\mathrm{Em} \%$ & $\mathrm{DI}^{* * *}$ & $\mathrm{Em} \%$ & $\mathrm{DD}^{* * * *}$ & $\mathrm{Em} \%$ \\
\hline Serrano & 124 & 1,8 & 18 & 3,7 & 670 & 0,4 & 275.809 & 5,9 \\
\hline Seridó & 96 & 1,4 & 34 & 7,1 & 712 & 0,4 & 253.090 & 5,4 \\
\hline Costa das Dunas & 5.816 & 86,0 & 351 & 72,8 & 173.094 & 95,8 & 3.556 .991 & 76,3 \\
\hline Costa Branca & 669 & 9,9 & 65 & 13,5 & 5.473 & 3,0 & 494.738 & 10,6 \\
\hline Agreste/Trairi & 58 & 0,9 & 14 & 2,9 & 739 & 0,4 & 79.918 & 1,7 \\
\hline Total & $\mathbf{6 . 7 6 3}$ & $\mathbf{1 0 0 , 0}$ & $\mathbf{4 8 2}$ & $\mathbf{1 0 0 , 0}$ & $\mathbf{1 8 0 . 6 8 8}$ & $\mathbf{1 0 0 , 0}$ & $\mathbf{4 . 6 6 0 . 5 4 6}$ & $\mathbf{1 0 0 , 0}$ \\
\hline
\end{tabular}

*Empregos em meios de hospedagem; **Meios de hospedagem; *** Demanda turística internacional; **** Demanda turística doméstica.

Fonte: BRASIL (2018). 
A tabela 5 categoriza os municípios, com exceção do Polo Costa das Dunas, com base na primeira formação dos polos turísticos sem levar em consideração os municípios incluídos e excluídos dos outros quatros polos pelo decreto 26.661/17. A tabela apresenta a tendência apresentada pelas outras tabelas, a concentração dos indicadores turísticos no polo Costa das Dunas, com destaque para as variáveis de empregos em meios de hospedagem e demanda turística internacional que aglomera nesse polo $86 \%$ e $95,8 \%$, respectivamente, dos números disponíveis.

Atualizando a categorização do Mapa do Turismo de 2017 de acordo com o decreto 26.661/17, a classificação de cluster para o Rio Grande do Norte resulta em dois municípios na categoria A, Natal e Tibau do Sul, ambas no PCD, e dois na categoria B, Mossoró, no Polo Costa Branca, e São Miguel do Gostoso, no PCD, doze na categoria $C$, trinta e seis na categoria $\mathrm{D}$, dez na categoria $\mathrm{E}$ e cinco sem categorização conforme especializa o mapa 3.

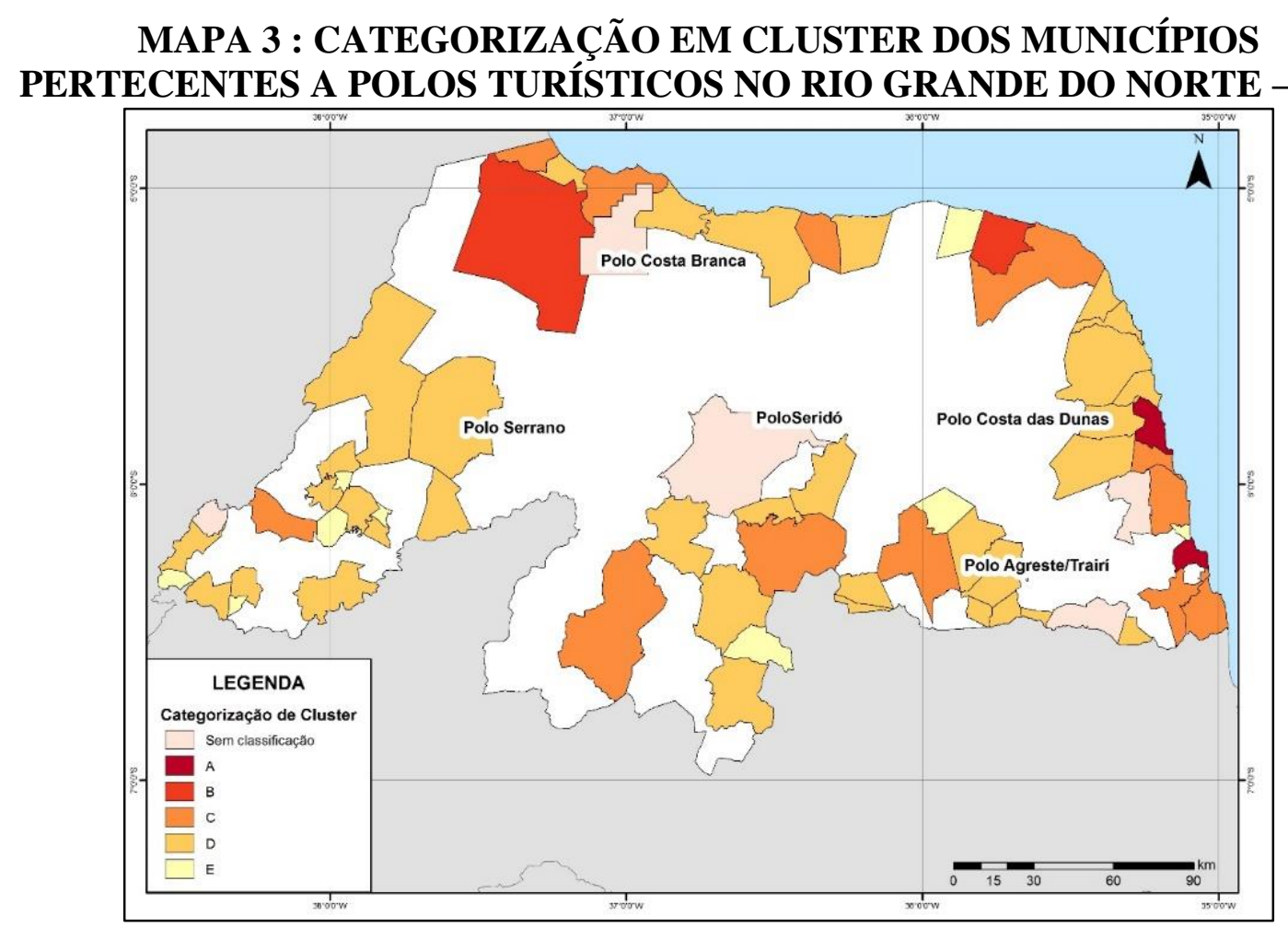

Fonte: Elaborado pelo autor, com base em BRASIL (2018).

A classificação de cluster para o RN destaca a fragilidade da atividade turística para o interior do estado, uma vez que essa atividade se especializa nos quatro municípios categorizados em A e B, que concentram os indicadores utilizados na composição do 
mapa do turismo, em relação aos demais cinquenta e um municípios classificados em $\mathrm{C}$, D e E, conforme demonstra a tabela 6:

TABELA 6: DADOS DO MAPA DO TURISMO DOS POLOS TURÍSTICOS DO RIO GRANDE DO NORTE POR AGRUPAMENTO DE CATEGORIAS - 2017

\begin{tabular}{|c|c|c|c|c|c|c|c|c|}
\hline Categ. & $\mathrm{EMH}^{*}$ & $\mathrm{Em} \%$ & $\mathrm{MH}^{* *}$ & $\mathrm{Em} \%$ & $\mathrm{DI}^{* * *}$ & $\mathrm{Em} \%$ & $\mathrm{DD}^{* * * *}$ & $\mathrm{Em} \%$ \\
\hline A e B & 6.009 & 89,5 & 301 & 64,9 & 172.499 & 95,7 & 3.398 .258 & 73,7 \\
\hline C, D e E & 708 & 10,5 & 163 & 35,1 & 7.775 & 4,3 & 1.211 .005 & 26,3 \\
\hline Total & $\mathbf{6 . 7 1 7}$ & $\mathbf{1 0 0 , 0}$ & $\mathbf{4 6 4}$ & $\mathbf{1 0 0 , 0}$ & $\mathbf{1 8 0 . 2 7 4}$ & $\mathbf{1 0 0 , 0}$ & $\mathbf{4 . 6 0 9 . 2 6 3}$ & $\mathbf{1 0 0 , 0}$ \\
\hline
\end{tabular}

*Empregos em meios de hospedagem; **Meios de hospedagem; *** Demanda turística internacional; $* * * *$ Demanda turística doméstica.

Fonte: BRASIL (2018).

Apesar do turismo fazer parte das atividades econômicas que contribuíram para reestruturação produtiva do Rio Grande do Norte, esta não é uma atividade de destaque econômico para os municípios classificados em C, D e E, ou seja, a prática do turismo, enquanto atividade econômica, não está capaz de contribuir para o desenvolvimento econômico.

\section{CONSIDERAÇÕES FINAIS}

Os autores Nonato Junior e Théry $(2017$, p.12) destacam que a atividade turística no Rio Grande do Norte atua como um motor para o desenvolvimento estadual, pois, “[...] movimenta um amplo sistema econômico, tendo uma das maiores taxas de turista por habitante no Brasil" em função "[...]de um vasto litoral tanto a leste como a norte é uma das situações naturais que permitem exploração de espaços bem diferenciados para este fim" [ibidem, p.12). Entretanto, essa não é uma atividade que consegue promover um desenvolvimento econômico para todo o estado, uma vez que está polarizada em Natal e quando se interioriza não consegue obter bons indicadores turísticos e econômicos para além do Polo Costa das Dunas, como os dos municípios de Tibau do Sul e São Miguel do Gostoso, com exceção do município de Mossoró, do Polo Costa Branca, que em função de suas atividades extrativistas-industriais consegue ser um destino categorizado como B no Mapa do Turismo ao atrair um significativo fluxo turístico.

No restante do estado a atividade turística ainda transita enquanto possibilidade com uma latência dormente para o desenvolvimento econômico. A ausência de políticas 
públicas específicas para estruturar essa atividade no interior do estado, como fez o PRODETUR/NE fase I e II para o litoral leste no PCD, condena o turismo a um discurso desenvolvimentista que aposta nesta atividade como o como a último baluarte para o crescimento econômico dos municípios dos demais polos turísticos, estruturado na crença que basta ter atrativos naturais e culturais para atrair turistas de origem internacional e nacional, esquecendo a consolidação do turismo no lugar é resultado de uma combinação interdependente do Estado, do Mercado e dos turistas, quando uma dessas variáveis é improfícua ou ausente nesta a equação a atividade turística não consegue ser uma opção para o desenvolvimento local ou estadual.

\section{REFERÊNCIAS}

ANDRADE, Manuel Correia de. O Nordeste e a Questão Regional. 2. ed. São Paulo: Ática, 1993.

AZEVEDO, Francisco Fransualdo. Reestruturação produtiva no Rio Grande do Norte.In: Mercator, v.12, número especial (2). Universidade Federal do Ceará: Fortaleza, 2013, p.113-132.

BANCO DO NORDESTE DO BRASIL S.A. Relatório Final de Projeto -Programa de Desenvolvimento do Turismo no Nordeste - Primeira Fase. 2005

BRASIL, II Plano Nacional de Desenvolvimento (1975-1979). Brasília, 1974. Portaria $\mathrm{N}^{\circ}$ 144, DE 27 de agosto de 2015. Estabelece a categorização dos municípios pertencentes às regiões turísticas do Mapa do Turismo Brasileiro, definido por meio da Portaria MTur no 313, de 3 de dezembro de 2013, e dá outras providências. 2015 .

Portal Brasileiro de Dados Abertos. Categorização dos Municípios Turísticos. 2018, disponível em 《< http://dados.gov.br/dataset/categorizacao >>. Acesso em 19 de jul. de 2019.

CARDOSO, Otomar Lopes. Terra de investir: O grande Rio Grande do Norte Artigos e reportagens. Rio de Janeiro, 1997.

COSTA, Jordana Medeiros. Uso corporativo do território e turismo no Rio Grande do Norte. Dissertação (Mestrado em Geografia) - UFRN, Natal, 2011.

CRUZ, Rita de Cássia Ariza da. Políticas de Turismo e (re)ordenamento de territórios no litoral do Nordeste do Brasil. Tese (Doutorado em Geografia) - USP, São Paulo, 1999. 
DANTAS, Eustógio Wanderley Correia; ALVES, Larissa da Silva Ferreira. Nordeste turístico e políticas de ordenamento do território. Fortaleza: Imprensa Universitária, 2017.

EMPROTURN. Indicadores de turismo 1990. Os números do turismo potiguar. Natal, 1991.

EQUIPE PCR. RELATÓRIO DE TÉRMINO DE PROJETO: Projeto: Programa de Desenvolvimento do Turismo no Nordeste (Prodetur/NE II). 2012.

FONSECA, Maria Aparecida Pontes. Espaço, políticas de turismo e competitividade. Edurfn: Natal, 2005.

FREIRE. Laura Lúcia Ramos. Modelo de Avaliação do PRODETUR/NE-II: base conceitual e metológica. Banco do Nordeste, Fortaleza, 2005.

FURTADO, Edna Maria. A “onda" do turismo na cidade do sol: a reconfiguração urbana de Natal. Tese (Doutorado em Ciências Sociais) - UFRN, Natal, 2005. A trajetória do turismo potiguar. In: NUNES, Elias; CARVALHO, Edilson Alves de; FURTADO, Edna Maria e FONSECA, Ma Aparecida Pontes (org). Dinâmica e gestão do território potiguar. Natal: EDUFRN, 2007, p. 233-244.

GOLÇALVES, Joyce de Souza; SERAFIM, Lia Sales. A Política Pública de Turismo no Rio Grande do Norte: um Estudo dos Impactos Econômicos e Socioculturais na Grande Natal. Anais do 30 encontro da ANPAD. Salvador, 2006, p.1-17.

HARVEY, David. Globalization and the "Spatial Fix". Geographische Revue. 2001.

A produção capitalista do espaço. São Paulo: Annablume, 2005.

IBGE. Cidades. 2019a. Disponível em

<<https://cidades.ibge.gov.br/brasil/rn/panorama〉>. Acesso em 19 de jul. de 2019.

Divisão Regional do Brasil. 2019b. Disponível em $<<$

https://ww2.ibge.gov.br/home/geociencias/geografia/default_div_int.shtm?c=1>>. Acesso em 19 de jul. de 2019.

LIMA, Dália Maria Maia Cavalcanti de. Geografia do Rio Grande do Norte: o turismo e o lugar. Natal, 2003.

RIO GRANDE DO NORTE. Decreto N 18.186, de 14 de abril de 2005. Institui o Polo Costa das Dunas e dá outras Providências. 2005a.

Decreto N. ${ }^{\circ} 18.187$, de 14 de abril de 2005. Institui o Polo Costa Branca e dá outras providências. $2005 \mathrm{~b}$.

Decreto $\mathrm{N}^{\circ} 18.429$, de 15 de agosto de 2005. Institui o Polo Turístico do Seridó e dá outras Providências. 2005c.

Lei Complementar N³39, de 24 de janeiro de 2007. Autoriza o Poder Executivo a criar a Empresa Potiguar de Promoção Turística S.A. (EMPROTUR), 
vinculada à Secretária de Estado do Turismo (SETUR), e dá outras providências. 2007.

. Decreto No 20.624, de 17 de julho de 2008. Institui o Polo Turístico Serrano e dá outras providências. 2008.

Institui o Polo Turístico Agreste/Trairi e dá outras providências. 2009.

. Plano de Desenvolvimento Integrado do Turismo Sustentável - PDITS -

Polo Costa das Dunas. 2011.

. Plano de Desenvolvimento Integrado do Turismo Sustentável - PDITS Polo Agreste/Trairí. 2016.

Decreto $\mathrm{N}^{\mathrm{o}} 26.661$, de 20 de fevereiro de 2017. Dispõe sobre os Polos

Turísticos do estado do Rio Grande do Norte e dá outras providências. 2017.

. Secretária de Turismo - SETUR. 2019. Disponível em

<<http://setur.rn.gov.br/>>. Acesso em 12 de jul. de 2019.

SALLUM JR, Brasilio; KUGELMAS, Eduardo. O Leviathan declinante: a crise brasileira dos anos 80. Estudos avançados. 5(13), 1991, p.145-159.

SETUR. Indicadores básicos do turismo 1991-1996. Natal, 1997.

2000.

Resumos dos indicadores básicos Rio Grande do Norte 1999 e 2000. Natal,

Indicadores básicos do turismo 1997. Natal, 1998.

Indicadores básicos do turismo 2002/2007. Natal, 2008.

Indicadores básicos do turismo 2006/2012. Natal, 2013.

SILVA, Marconi Gomes. Dinâmica econômica recente e reestruturação produtiva no Rio Grande do Norte (1970-2000). In: História econômica \& história de empresas. Vol. 17, nº1. 2014, 257-294.

SMITH, Neil. Desenvolvimento desigual. Rio de Janeiro: Bertrand Brasil, 1988.

VARGAS, Juliano; FELIPE; Ednilson Silva. Década de 1980: as crises da economia e do Estado Brasileiro, suas ambiguidades institucionais e os movimentos de desconfiguração do mundo do trabalho. Revista de Economia, v.41, n.3 (ano 39), 2015, p.127-148.

Recebido em Outubro de 2019.

Aprovado em Dezembro de 2019.

Publicado em Dezembro de 2019. 